\title{
Dynamic Control of Chromosome Topology and Gene Expression by a Chromatin Modification
}

\author{
Qian Bian, ${ }^{1}$ Erika C. Anderson, Katjuša Brejc, and Barbara J. Meyer \\ Howard Hughes Medical Institute and Department of Molecular and Cell Biology, University \\ of California at Berkeley, Berkeley, California 94720-3204 \\ Correspondence: bjmeyer@berkeley.edu
}

\begin{abstract}
The function of chromatin modification in establishing higher-order chromosome structure during gene regulation has been elusive. We dissected the machinery and mechanism underlying the enrichment of histone modification H4K20me1 on hermaphrodite X chromosomes during Caenorhabditis elegans dosage compensation and discovered a key role for H4K20me1 in regulating X-chromosome topology and chromosome-wide gene expression. Structural and functional analysis of the dosage compensation complex (DCC) subunit DPY-21 revealed a novel Jumonji C demethylase subfamily that converts H4K20me2 to H4K20me1 in worms and mammals. Inactivation of demethylase activity in vivo by genome editing eliminated H4K20me1 enrichment on X chromosomes of somatic cells, increased X-linked gene expression, reduced X-chromosome compaction, and disrupted X-chromosome conformation by diminishing the formation of topologically associated domains. H4K20me1 is also enriched on the inactive $\mathrm{X}$ of female mice, making our studies directly relevant to mammalian development. Unexpectedly, DPY21 also associates specifically with autosomes of nematode germ cells in a DCC-independent manner to enrich H4K20me1 and trigger chromosome compaction. Thus, DPY-21 is an adaptable chromatin regulator. Its H4K20me2 demethylase activity can be harnessed during development for distinct biological functions by targeting it to diverse genomic locations through different mechanisms. In both somatic cells and germ cells, H4K20me1 enrichment modulates three-dimensional chromosome architecture, demonstrating the direct link between chromatin modification and higher-order chromosome structure.
\end{abstract}

Chromatin modification and three-dimensional (3D) chromosome structure play central roles in regulating gene expression (Vieux-Rochas et al. 2015; Dekker and Mirny 2016; Soshnev et al. 2016; Nora et al. 2017; Schuettengruber et al. 2017). However, the role of histone modifications in establishing higher-order chromosome structure during gene regulation has been elusive.

Histone modifications are known to alter the interactions between nucleosomes that govern the compaction state of a chromatin fiber (Francis et al. 2004; Lu et al. 2008; Kalashnikova et al. 2013). However, the effect of histone modifications on higher-order chromosome organization beyond chromatin-fiber compaction is not well understood. Only recently has super-resolution imaging shown that chromatin domains enriched in H3K27me3 and Polycomb proteins adopt unique folded states (Boettiger et al. 2016). Once the Polycomb repressive complex 1 is recruited to H3K27me3-enriched chromatin, it generates chromatin domains 20-140 kb in size (Kundu et al. 2017). These domains are distinct from topologically associating domains (TADs), which are self-interacting genomic regions up to $1 \mathrm{Mb}$ in size that permit loci within a domain to interact with each other but insulate these loci from interactions with loci in other TADs (Nora et al. 2013).

We analyzed X-chromosome dosage compensation in the nematode Caenorhabditis elegans to explore the relationship between chromatin modification and higher-order chromosome structure during chromosome-wide gene regulation. Dosage compensation is achieved by a 10 -subunit dosage compensation complex (DCC) that binds to both hermaphrodite $\mathrm{X}$ chromosomes via sequence-dependent recruitment elements on $\mathrm{X}$ (rex sites) to reduce transcription by half(Fig. 1A,C; Csankovszki et al. 2009; Jans et al. 2009; Mets and Meyer 2009; Meyer 2010). This chromosome-wide modulation of gene expression ensures that males $(\mathrm{XO})$ and hermaphrodites $(\mathrm{XX})$ express equivalent levels of $\mathrm{X}$-chromosome products despite their unequal dose of X chromosomes. Five DCC subunits (Fig. 1B) are homologous to subunits of condensin, a complex conserved from yeast to man that compacts and resolves chromosomes in preparation for chromosome segregation during mitosis and meiosis (Csankovszki et al. 2009; Mets and Meyer 2009; Meyer 2010; Hirano 2016). The similarity between the DCC and condensin suggested that the DCC might remodel the structure of $\mathrm{X}$ to achieve gene repression.

Indeed, the DCC imposes a distinct higher-order structure onto both hermaphrodite $\mathrm{X}$ chromosomes while repressing gene expression. It remodels the topology of $\mathrm{X}$ into a sex-specific spatial conformation distinct from that of autosomes or male $\mathrm{X}$ chromosomes by forming TADs of $\sim 1 \mathrm{Mb}$ (Crane et al. 2015). The highest-affinity rex sites are located at TAD boundaries and several observations support a model in which DCC-dependent looping interactions between these high-affinity rex sites direct TAD formation (Crane et al. 2015). (1) Interactions between rex sites are

\footnotetext{
${ }^{1}$ Present address: Shanghai Institute of Precision Medicine, Ninth People’s Hospital, Shanghai Jiao Tong University School of Medicine, Shanghai, China (C) 2017 Bian et al. This article is distributed under the terms of the Creative Commons Attribution-NonCommercial License, which permits reuse and redistribution, except for commercial purposes, provided that the original author and source are credited.
} 


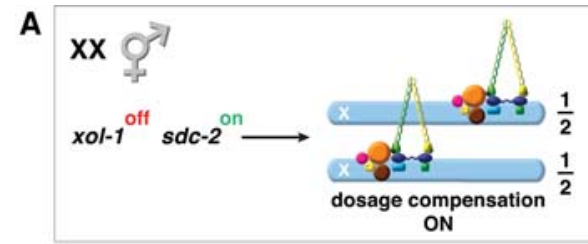

в

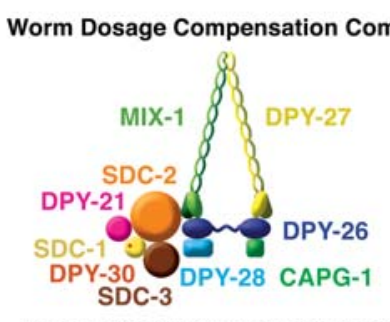

reduce $\mathrm{X}$-chromosome expression

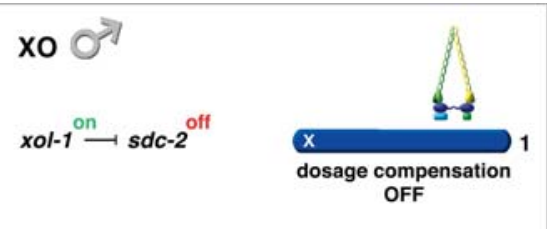

Condensin Complex

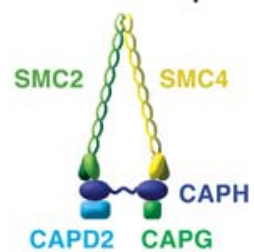

condense mitotic and meiotic chromosomes

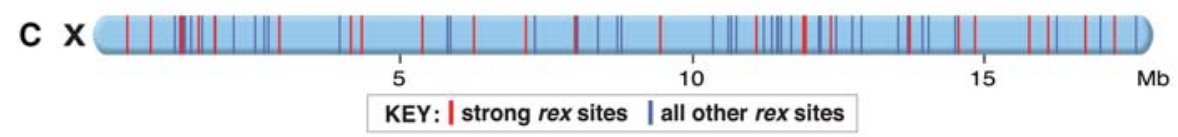

D

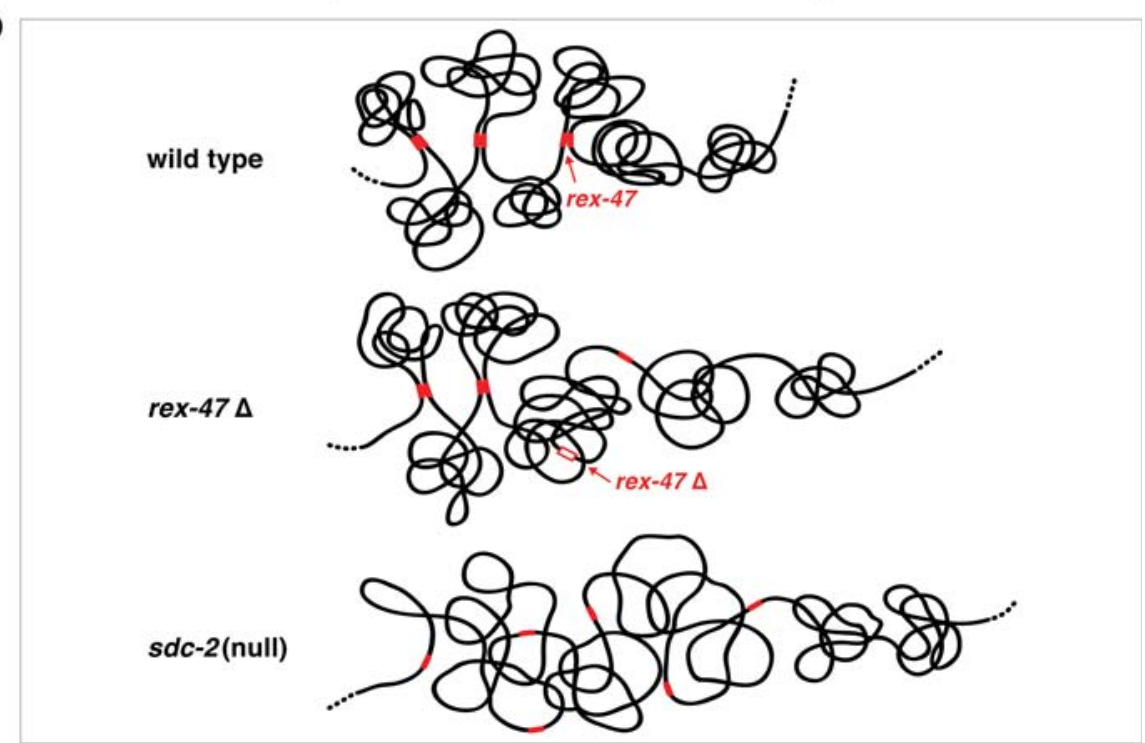

Figure 1. Overview of dosage compensation in Caenorhabditis elegans. $(A)$ In XX hermaphrodites, a dosage compensation complex (DCC) binds to both $\mathrm{X}$ chromosomes to reduce gene expression by half, thereby equalizing expression with that from the single male $\mathrm{X}$. The product of the XX-specific gene $s d c$-2 triggers assembly of the DCC onto X. In XO males, $x o l-1$, the male-specific regulator of sex determination and dosage compensation, represses $s d c-2$, thereby preventing the DCC from binding to the male X. $(B)$ The DCC compared with condensin I of other eukaryotes. The DCC condensin subunits (MIX-1, DPY-27, DPY-26, DPY-28, and CAPG-1) are color matched to their condensin I homologs (Csankovszki et al. 2009; Mets and Meyer 2009; Meyer 2010). All DCC condensin subunits except DPY-27 also function in other condensins that act in C. elegans mitosis and meiosis. The DPY-27 paralog SMC-4 (not shown) replaces DPY-27 in mitotic and meiotic condensins. The DCC likely arose by duplicating the gene encoding SMC-4 and modifying it to create DPY-27 for a specific role in gene expression (Hagstrom et al. 2002). In addition to condensin subunits, the DCC also includes a novel XX-specific protein with a large coiled-coil domain (SDC-2) (Dawes et al. 1999) that triggers assembly of the DCC onto X chromosomes. Two DCC subunits aid SDC-2 in recruiting the complex to X, SDC-3 (a zinc finger protein) and DPY-30 (a subunit of the MLL/COMPASS H3K4me3 methyltransferase complex) (Klein and Meyer 1993; Hsu et al. 1995; Davis and Meyer 1997; Pferdehirt et al. 2011). Two subunits, SDC-1 (a zinc finger protein) and DPY-21, are required for DCC activity but not assembly (Nonet and Meyer 1991; Yonker and Meyer 2003). DPY-21 is a Jumonji C H4K20me2 demethylase described here and in (Brejc et al. 2017). (C) DCC recruitment sites across $\mathrm{X}$ chromosomes. The DCC recruitment elements on X (rex) were discovered by the combination of genome-wide approaches (ChIP-chip and ChIP-seq) to identify DCC-binding sites without regard to autonomous recruitment ability and a functional approach in vivo to assess DCC binding to sites detached from X (Jans et al. 2009; Crane et al. 2015). rex sites are distributed across X and confer X-chromosome specificity to dosage compensation. DCC binding to rex sites facilitates DCC spreading across X to sites that cannot bind the complex if detached from X (Pferdehirt et al. 2011). Several of the strongest rex sites (red) are essential for formation of topologically associated domains (TADs). (D) Cartoon model of TAD formation on a segment of X. (Top) The DCC remodels the topology of X into a hermaphrodite-specific conformation by forming TADs. DCC-dependent looping interactions between high-affinity rex sites located at TAD boundaries direct TAD formation (Crane et al. 2015). (Middle) Deletion of the high-affinity site rex-47 located at a DCC-dependent TAD boundary eliminates boundary formation (Crane et al. 2015). (Bottom) Severe disruption of DCC binding by an $s d c-2$ mutation eliminates formation of all DCC-dependent TADs on X (Crane et al. 2015). 
A Worm dosage compensated X chromosomes of $\sigma^{\prime \prime}$ have enriched H4K20me1

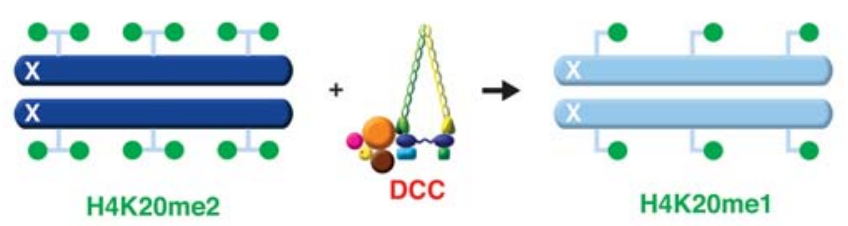

Mammalian inactive $X$ of $Q$ has enriched H4K20me1

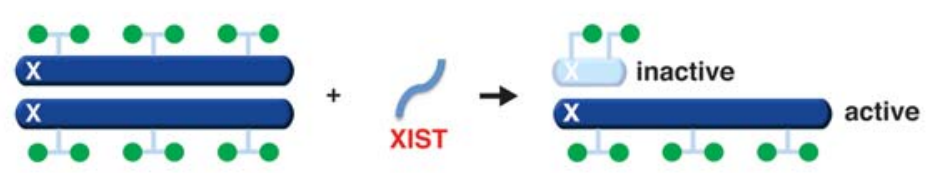

B

H4K20 Methylation

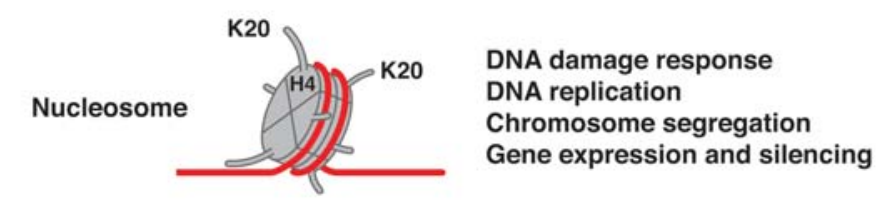

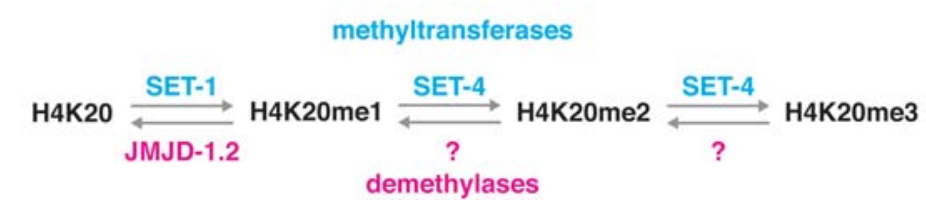

Figure 2. H4K20me1 enrichment on the repressed $\mathrm{X}$ chromosomes is a shared feature of diverse dosage compensation strategies. (A) Dosage-compensated X chromosomes of C. elegans hermaphrodites have dosage compensation complex (DCC)-dependent H4K20me1 enrichment. H4K20me1 enrichment on the inactive X chromosome of female mammals requires the long noncoding RNA XIST that triggers X inactivation. For neither strategy had the mechanism of H4K20me1 enrichment been determined. $(B)$ H4K20 methylation controls myriad nuclear functions, but the mechanisms that regulate different H4K20 methylation states are not well understood. H4K20me2/me3 demethylases had not been identified.

among the most prominent long-range interactions along the X chromosome, and disruption of the DCC abolishes the interactions and TAD structure. (2) The stronger the rex sites, the more frequent are the DCC-dependent interactions among them. (3) Deletion of a single high-affinity rex site at a TAD boundary eliminates formation of the TAD boundary. Thus, not only does a condensin complex play a key role in compacting and resolving mitotic and meiotic chromosomes, it plays a central role in shaping the 3D landscape of interphase chromosomes.

During this chromosome remodeling process, the chromatin modification H4K20me1 becomes selectively enriched on both hermaphrodite X chromosomes in a DCCdependent manner (Fig. 2A; Liu et al. 2011; Vielle et al. 2012; Wells et al. 2012; Kramer et al. 2015). H4K20me1 is also selectively enriched on the inactive $\mathrm{X}$ chromosome of female mammals, highlighting a shared feature of diverse dosage compensation strategies (Fig. 2A; Kohlmaier et al. 2004). In neither case had the mechanism of H4K20me1 enrichment been discovered. Furthermore, the effect of the H4K20me1 modification on gene regulation and chromosome structure had not been determined.

In general, the role of $\mathrm{H} 4 \mathrm{~K} 20 \mathrm{me} 1$ in gene regulation has remained a mystery because of its contribution to both gene activation and gene repression in different contexts (Beck et al. 2012). Although H4K20 methylation has been implicated in many nuclear functions beyond gene regulation, such as DNA replication and repair, mitotic chromosome condensation, and cell cycle control, the mechanisms that regulate different H4K20 methylation states and transduce them into correctly executed nuclear functions are not understood (Fig. 2B; Beck et al. 2012; Jorgensen et al. 2013; van Nuland and Gozani 2016). We discovered the machinery and mechanism that catalyze H4K20me1 enrichment on nematode X chromosomes and the impact of H4K20me1 on higher-order chromosome structure and gene regulation (Brejc et al. 2017).

In principle, H4K20me1 enrichment on nematode $\mathrm{X}$ chromosomes could occur by activating the methyltransferase that converts H4K20 to H4K20me1 (SET-1), by blocking the methyltransferase that converts H4K20me1 to H4K20me2/me3 (SET-4), by blocking the demethylase that converts H4K20me1 to H4K20 (JMJD$1.1 / 1.2$ ), or by activating an unknown demethylase that converts H4K20me2 to H4K20me1 (Fig. 2B). Although H4K20me 2 is the most abundant form of H4K20 in eukaryotic cells (Pesavento et al. 2008), only a neuronspecific H4K20me2 demethylase had been reported 
(Wang et al. 2015). No H4K20me2 demethylase had been identified that could function during the dosage compensation process. Indeed, published models featured the inhibition of SET-4 as the likely mechanism for H4K20me1 enrichment on X in C. elegans (Vielle et al. 2012; Wells et al. 2012; Kramer et al. 2015). In contrast, our X-ray crystallography and biochemical assays of the DCC subunit DPY-21 revealed a new subfamily of Jumonji C (JmjC) histone demethylases that converts H4K20me2 to H4K20me1 in vitro and is widely conserved from worms to mammals (Brejc et al. 2017). We showed that DPY-21 catalyzes H4K20me1 enrichment on $\mathrm{X}$ in vivo, and H4K20me1 enrichment, in turn, helps remodel the higher order of structure of X chromosomes (Brejc et al. 2017).

\section{SUBUNIT DPY-21 AND MOUSE ROSBIN PROTEIN ARE THE FIRST JUMONJI C (JmjC) DEMETHYLASES THAT CONVERT H4K20me2 TO H4K20me1}

Although amino acid sequence analysis failed to identify a demethylase domain in any of the 10 DCC subunits, structure prediction programs suggested homology between the carboxy-terminal domain of DPY-21 and JmjC domain-containing lysine demethylases (KDMs), despite low (15\%) sequence identity. JmjC KDMs are $\mathrm{Fe}^{2+}$ and $\alpha$-ketoglutarate $(\alpha-\mathrm{KG})$-dependent dioxygenases that demethylate lysines in histone and nonhistone proteins (Markolovic et al. 2016). This potential connection was investigated by determining a $1.8 \AA$ crystal structure of the C. elegans DPY-2 $1^{1210-1617}$ fragment that encompasses the putative JmjC domain (Brejc et al. 2017). Comparisons to known structures (Holm and Rosenstrom 2010) revealed DPY-21 to be a JmjC domain-containing protein most similar to the JmjC KDMs (Fig. 3A,B).

Like other JmjC KDMs, the DPY-21 ${ }^{1210-1617}$ structure includes a JmjC domain that is folded into a doublestranded $\beta$-helix (DSBH) and surrounded by a Jumonji $\mathrm{N}(\mathrm{Jmj} \mathrm{N})$ domain, a $\beta$-hairpin motif, and a mixed domain (Fig. 3A; Chen et al. 2006). The DPY-21 DSBH core bears facial triad residues (H1452, D1454, and H1593) that chelate $\mathrm{Fe}^{2+}$ and form an active site (Fig. 3B). An $\alpha-\mathrm{KG}$ molecule coordinates $\mathrm{Fe}^{2+}$ in a bidentate manner, and a water molecule completes the octahedral coordination of $\mathrm{Fe}^{2+}$ (Fig. 3B). The $\alpha-\mathrm{KG}$ is further stabilized by hydrogen bonding to side chains of T1449 and Y1585 and also by hydrogen bonding to side chains of W1410, K1526, and $\mathrm{S} 1603$ via water molecules. In addition, $\alpha-\mathrm{KG}$ forms van der Waals contacts with A1499, L1587, and F1595.

The DPY-21 carboxy-terminal domain is similar (33\% identity) to carboxy-terminal domains of metazoan proteins named round spermatid basic proteins 1 (ROSBIN) (Fig. 3C; Yonker and Meyer 2003). Mouse ROSBIN, an essential protein with limited biochemical characterization, is expressed in embryos and male gonads (Takahashi et al. 2004; Koscielny et al. 2014). Structure-guided sequence comparison of ROSBIN proteins with DPY-21 showed that all residues that interact with $\mathrm{Fe}^{2+}$ and $\alpha-$ $\mathrm{KG}$ are conserved. Moreover, sequence conservation ex- tends to regions participating in histone peptide binding, as defined by JmjC KDM structures (Markolovic et al. 2016), suggesting that ROSBINs may also be JmjC demethylases that share substrate specificity.
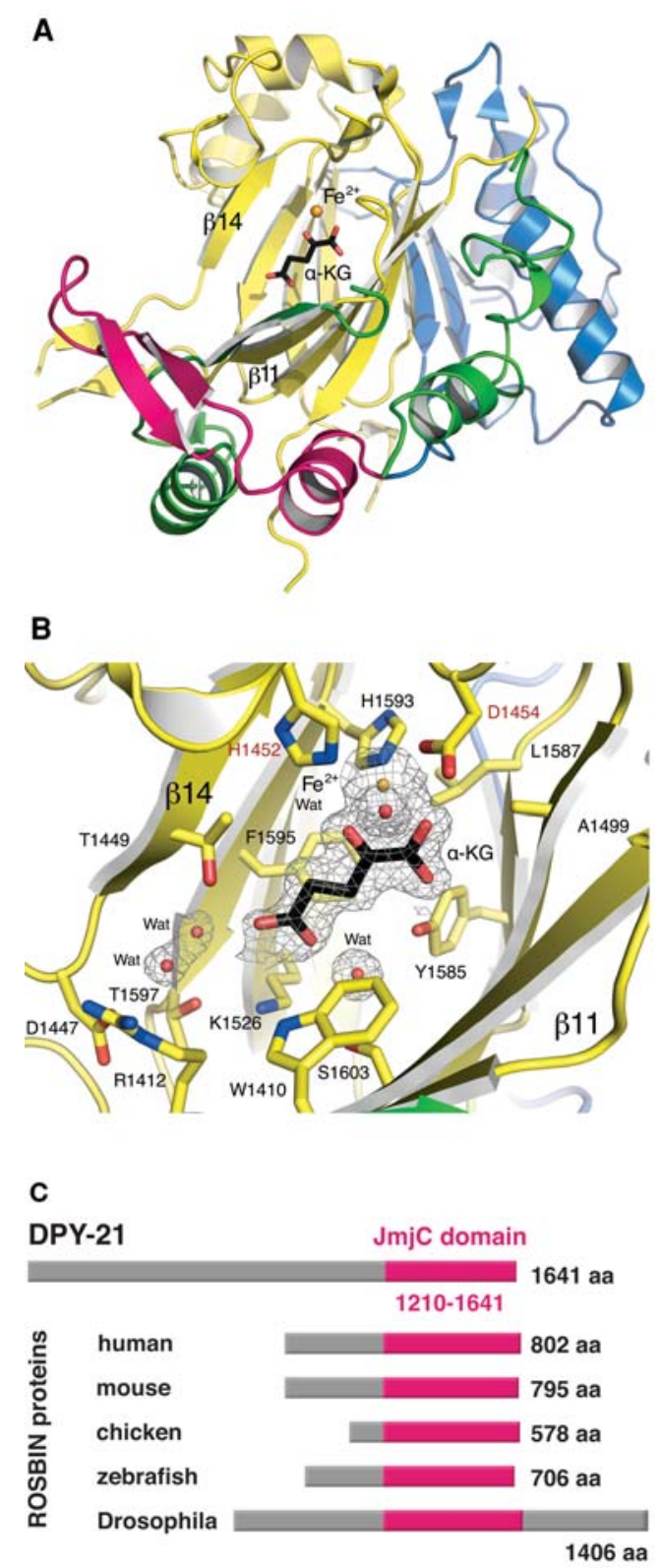

Figure 3. $1.8 \AA$ structure of the DPY-21 JmjC demethylase domain. $(A)$ DPY-21 $1^{1210-1617}$ structure in complex with $\alpha-K G$ (black) and $\mathrm{Fe}^{2+}$ (orange) showing JmjC domain (yellow), JmjN (blue), $\beta$-hairpin (magenta), and mixed domain (green). (Adapted from Brejc et al. 2017.) (B) Active site of DPY$21^{1210-1617}$ showing JmjC domain residues (yellow) in complex with $\mathrm{Fe}^{2+}$ (orange), $\alpha-\mathrm{KG}$ (black), and water molecules (red). Facial triad residues H1452 and D1454 (red letters) were changed to alanines for in vitro and in vivo studies. The electron density, $2 F_{0}-F_{\mathrm{c}}(\mathrm{mesh})$, contoured at $1.0 \sigma$ above the mean is shown for $\mathrm{Fe}^{2+}, \alpha-\mathrm{KG}$, and water molecules. (Adapted from Brejc et al. 2017.) (C) Evolutionary conservation of DPY-21 JmjC domain (magenta) in ROSBIN proteins across species. 
Assays performed in vitro with modified histones showed that both DPY-21 and mROSBIN convert H4K20me2 to H4K20me1, demonstrating the evolutionary conservation of a novel H4K20me $2 \mathrm{JmjC}$ demethyase activity (Brejc et al. 2017). mRosbin also demethylated an H4K20me2 peptide in vitro (Brejc et al. 2017). Substitution of facial triad residues (H1452A and D1454A) in DPY-21 abolished enzymatic activity, and both proteins were inactive without their $\mathrm{Fe}^{2+}$ and $\alpha-\mathrm{KG}$ cofactors (Brejc et al. 2017). Furthermore, both DPY-21 and mROSBIN have a strong preference for H4K20me2 as a substrate, because neither protein was active in vitro with H4K20me1, H4K20me3, or histone H3 methyl substrates (Brejc et al. 2017).

The single previously identified H4K20me2 demethylase (nLSD1) is a neuronal-specific isoform of LSD1 that uses different chemistry from JmjC domains (Wang et al. 2015). nLSD1 is a flavin-dependent monoamine oxidase that demethylates both H4K20me2 and H4K20me1. The only JmjC H4K20 demethylases identified before DPY21 and ROSBIN have specificity for H4K20me3 (PHF2) and H4K20me1 (PHF8) (Liu et al. 2010; Qi et al. 2010; Stender et al. 2012). Both have an amino-terminal PHD domain required for demethylase activity in vitro, which occurs only in the context of nucleosomes. In contrast, DPY-21 and mROSBIN lack PHD and other chromatininteracting domains and only require the JmjC domain for substrate recognition, allowing them to demethylate H4K20me2 in vitro on histone and histone peptides. These structural and biochemical findings merit classifying DPY-21 and ROSBIN proteins as a new subfamily of JmjC demethylases, the KDM9 subfamily.

\section{THE DPY-21 JmjC DEMETHYLASE ACTS IN A CELL-CYCLE-DEPENDENT MANNER TO ENRICH H4K20me1 ON X CHROMOSOMES OF SOMATIC CELLS}

H4K20me1 enrichment on hermaphrodite X chromosomes occurs in a cell cycle-dependent manner, during interphase but not mitosis, where H4K20me1 levels are uniformly elevated on all chromosomes (Fig. 4A,B; Brejc et al. 2017). H4K20me1 enrichment is not evident on interphase $\mathrm{X}$ chromosomes before the 200-cell stage of embryogenesis and only becomes reliably detectable on $\mathrm{X}$ in most interphase cells around the 300-350-cell stage, long after initial recruitment of SDC-2 and other DCC subunits to X (30-40-cell stage) (Fig. 4A; Brejc et al. 2017). In contrast to other DCC subunits, DPY-21's association with $\mathrm{X}$ is precisely coincident with the timing of H4K20me1 enrichment on X. Moreover, DPY-21 is not bound to mitotic chromosomes, unlike other DCC subunits (Fig. 4B). These results suggest that DPY-21 demethylates H4K20me2 on X to enrich H4K20me1.

In three different genome-engineered strains expressing DPY-21 variants with substitutions in JmjC facial triad amino acids (H1452A, D1454A, or H1452A/ D1454A), sex-specific enrichment of H4K20me1 was absent from interphase $\mathrm{X}$ chromosomes (Fig. 4A). In contrast, HK20me1 levels were unaffected on mitotic chromosomes (Fig. 4A,B; Brejc et al. 2017).

In chromatin immunoprecipitation sequencing (ChIPseq) experiments measuring the genome-wide distribution of H4K20me1 in wild-type and dpy-21(JmjC)-mutant embryos using a spike-in control to normalize read count, H4K20me1 was enriched on X compared to autosomes in wild-type but not in demethylase-mutant embryos (Fig. 4C; Brejc et al. 2017). Loss of H4K20mel enrichment on $\mathrm{X}$ in $d p y-21(\mathrm{JmjC})$ mutants coupled with the timing of DPY-21's association with $\mathrm{X}$ during interphase and DPY-21's absence from mitotic chromosomes indicate that JmjC demethylase activity is responsible for $\mathrm{X}$ enrichment of H4K20me1.

\section{LOSS OF H4K20me2 DEMETHYLASE ACTIVITY DISRUPTS DOSAGE COMPENSATION AND ELEVATES X-LINKED GENE EXPRESSION}

Prior studies aimed at understanding the role of H4K20me1 enrichment on X during dosage compensation used RNAi-mediated knockdown of the methyltransferase gene set-1 to reduce H4K20me1 levels genomewide or mutation of set-4 to block the progression of $\mathrm{H} 4 \mathrm{~K} 20 \mathrm{me} 1$ to $\mathrm{H} 4 \mathrm{~K} 20 \mathrm{me} 2 / \mathrm{me} 3$, thereby increasing H4K20me1 levels across all chromosomes (Vielle et al. 2012; Wells et al. 2012; Kramer et al. 2015). The resulting genome-wide changes in gene expression made it difficult to assess the specific importance of H4K20me1 levels on $\mathrm{X}$ during dosage compensation. Furthermore, interpretation of genetic assays evaluating dosage compensation defects (Vielle et al. 2012; Wells et al. 2012) was confounded, in retrospect, by the finding that set-1 knockdown causes synergistic lethality in both sexes from defective mitosis (Brejc et al. 2017).

In contrast, the highly specific $d p y-21(\mathrm{JmjC})$ mutations enabled us to eliminate H4K20me1 enrichment selectively from $\mathrm{X}$ and show through genetic assays and direct RNA measurements that loss of demethylase activity disrupts dosage compensation. The role of H4K20me1 was assessed by first asking whether $d p y$-21(JmjC) mutations suppress the XO-specific lethality caused by xol-1 mutations, which inappropriately activate the DCC in males. xol-1, the master regulator of sex-determination and dosage compensation, acts in $\mathrm{XO}$ embryos to turn off the hermaphrodite pathway of sexual differentiation and to prevent DCC binding to the single male $\mathrm{X}$ by repressing $s d c$-2, the XX-specific trigger of DCC binding to X (Miller et al. 1988; Rhind et al. 1995; Dawes et al. 1999). xol-1 mutant XO animals die from reduced X-linked gene expression. If the JmjC catalytic activity is important for reducing $\mathrm{X}$ expression during dosage compensation, mutations that inactivate this demethylase should suppress the xol-1 XO-specific lethality. Indeed, JmjC mutations prevented the death of xol-1 XO males, indicating that dpy-21(JmjC) mutations disrupt dosage compensation, and H4K20mel enrichment is important for the dosage compensation mechanism (Brejc et al. 2017). 
A $d p y-21(\mathrm{JmjC})$ mutation abolishes $\mathrm{X}$ enrichment of H4K20me1 but not $\mathrm{X}$ binding of DPY-21

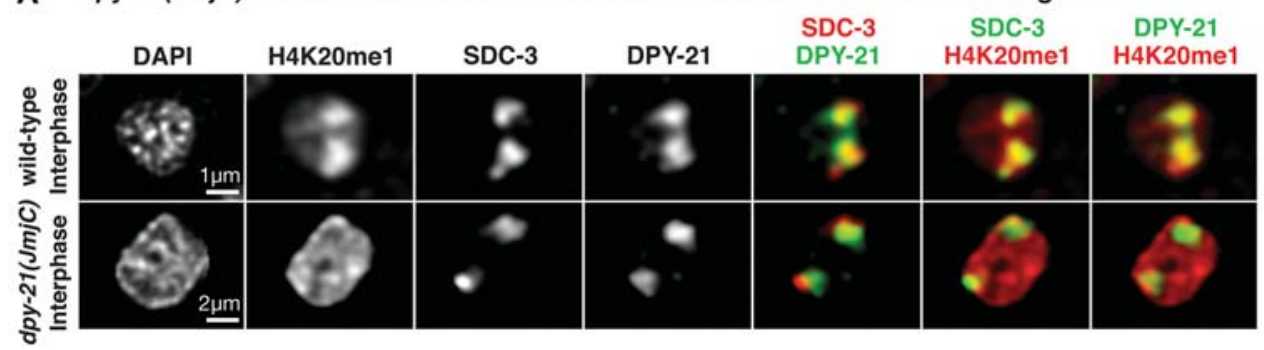

B Cell-cycle-dependent activity of DPY-21 controls H4K20me1 levels in interphase not mitosis

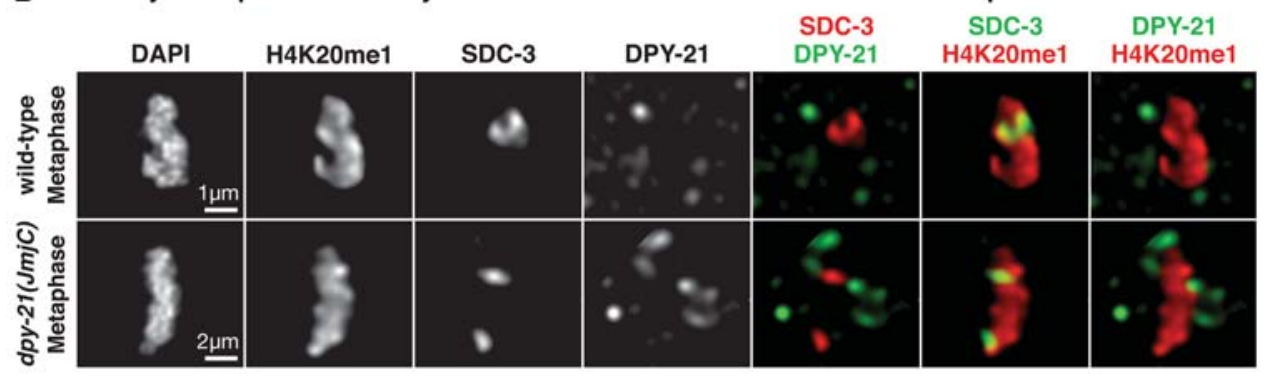

C Genome-wide distribution studies show the JmjC demethylase controls H4K20me1 levels on X Chromosome X ChIP-seq of H4K20me1
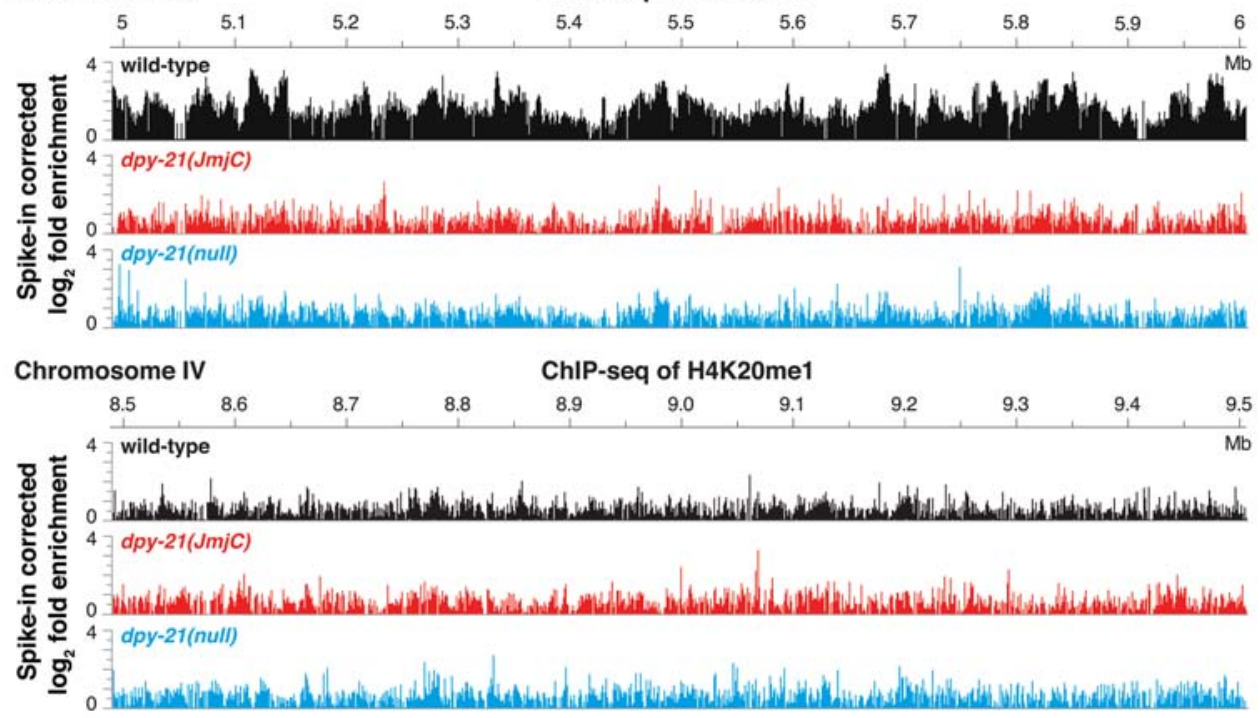

Figure 4. DPY-21 JmjC H4K20me2 demethylase enriches H4K20me1 on X in vivo. ( $A$ ) Confocal images of an interphase nucleus from a 376-cell wild-type embryo (top) and an interphase nucleus from a 335-cell dpy-21(JmjC) mutant embryo (bottom) stained with DAPI and antibodies to DPY-21, dosage compensation complex (DCC) subunit SDC-3, and H4K20me1. The JmjC mutation does not affect binding of DPY-21 to X, but it does disrupt the H4K20me1 enrichment on X. (B) Metaphase nucleus from a 376-cell wild-type embryo (top) and metaphase nucleus from a 335-cell dpy-21 (JmjC) mutant embryo (bottom) stained as in $A$. During mitosis, DPY-21 dissociates from X, but SDC-3 remains bound. The JmjC mutation does not affect the H4K20me1 level on mitotic chromosomes. (C) ChIP-seq profiles show spike-in-corrected H4K20mel enrichment in representative regions of chromosome X and chromosome IV in wild-type, $d p y-21(\mathrm{JmjC})$, and $d p y-21$ (null) mutant embryos. X enrichment of H4K20me1 is lost in $d p y-21$ mutants, but H4K20me1 levels are unchanged on autosomes. (Based on data from Brejc et al. 2017.)

The importance of demethylase activity in repressing gene expression predicts that blocking H4K20me $2 / \mathrm{me} 3$ production via a set-4 mutation should prevent the rescue of xol-1 XO males by $d p y-21(\mathrm{JmjC})$ mutations. This prediction held true, providing strong genetic evidence that production of $\mathrm{H} 4 \mathrm{~K} 20 \mathrm{me} 2 / \mathrm{me} 3$ on $\mathrm{X}$ is an intermediate step in the enrichment of H4K20me1 on X (Brejc et al. 2017).
The effect of $d p y-21(\mathrm{JmjC})$ mutations on X-chromosome gene expression was shown directly by RNA-seq experiments. Cumulative plots comparing the distribution of fold changes in gene expression on $\mathrm{X}$ chromosomes and autosomes between wild-type and $d p y$ - 21 mutant embryos revealed that $\mathrm{X}$-chromosome gene expression was significantly elevated relative to that of each individual autosome in $d p y-21(\mathrm{JmjC})$ mutants (Fig. 5). Similar re- 

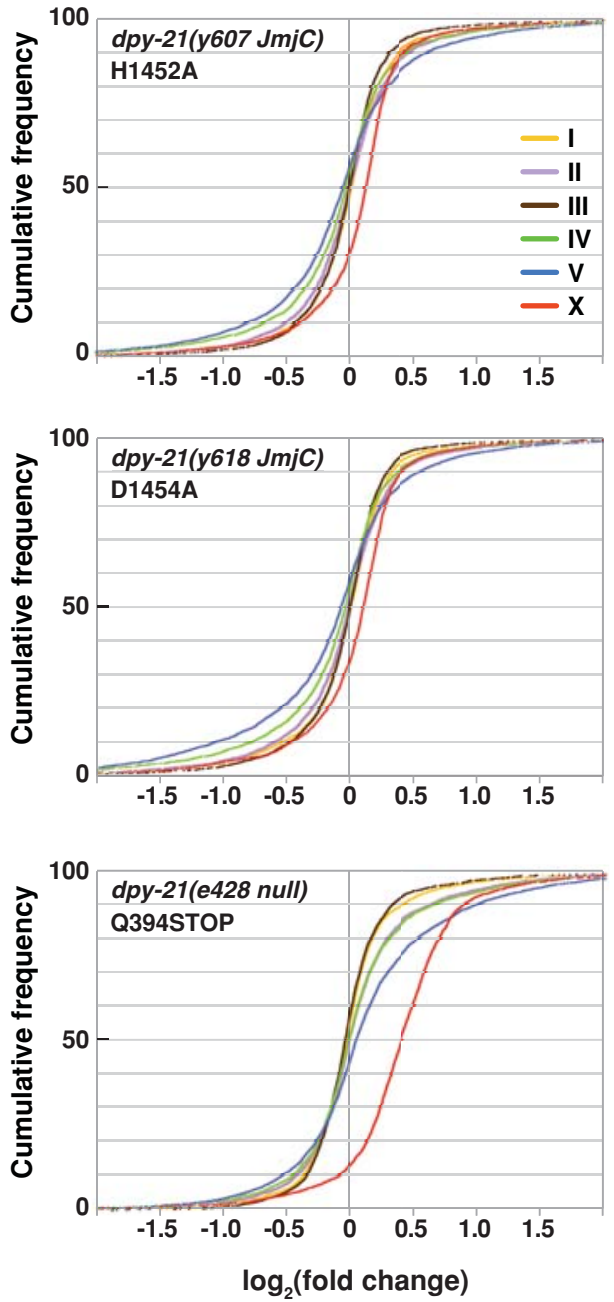

Figure 5. X-chromosome gene expression is elevated relative to autosomes in $d p y-21(\mathrm{JmjC})$ mutants. Cumulative plots show the distribution of expression changes for genes on $\mathrm{X}$ and for each individual autosome in $d p y-21(\mathrm{JmjC})$ mutant versus wild-type embryos as assayed by RNA-seq. The $x$-axis represents the $\log _{2}$ fold change in expression. X-chromosome gene expression is elevated compared to that of each autosome in $d p y-21(y 607 \mathrm{JmjC})$, dpy-21(y618 JmjC), dpy-21(e428 null) mutants $\left(P<2.2 \times 10^{-16}\right.$, one-sided Wilcoxon rank-sum test). (Based on data from Brejc et al. 2017.)

sults were obtained for $d p y$-21(null) mutants, but the relative elevation in X expression was somewhat greater (Fig. 5), consistent with the more severe mutant phenotypes for null mutants (Brejc et al. 2017). These findings show that DPY-21's demethylase activity, and by extension the enrichment of H4K20me1 on X, functions in vivo to help repress X-chromosome gene expression.

Chromatin with posttranslationally modified histones can recruit specialized proteins ("readers") to control the structure of nucleosome arrays and regulate gene expression (Soshnev et al. 2016). In particular, chromatin readers of the malignant brain tumor (MBT) repeat protein family associate with nucleosomes enriched in H4K20me1 or H4K20me2, help compact the chromatin fiber, and repress gene expression (Trojer et al. 2007; Blanchard et al. 2014).
However, knockout of the two C. elegans MBT repeat proteins, $m b t r-1$ and lin-61, failed to suppress xol-1 XO lethality, unlike $d p y-21(\mathrm{JmjC})$ mutations, indicating a lack of dosage compensation defects (Brejc et al. 2017). This result implies that if $\mathrm{H} 4 \mathrm{~K} 20 \mathrm{mel}$-binding proteins modulate $\mathrm{X}$-chromosome conformation and gene repression, they must belong to an unidentified family of H4K20me1 readers. As alternatives, H4K20me1 might antagonize other proteins with chromatin-modifying activities, or less likely, it might control chromatin folding directly.

\section{H4K20me1-DRIVEN REMODELING OF X-CHROMOSOME TOPOLOGY}

$\mathrm{X}$ chromosomes undergo changes in conformation during dosage compensation. Cytological studies measuring the volumes of chromosome territories showed that DCC binding increases the compaction state of $\mathrm{X}$ chromosomes (Lau et al. 2014). Genome-wide chromosome conformation capture (Hi-C) studies showed the DCC remodels X chromosomes into a unique, sex-specific spatial conformation, distinct from that of autosomes by inducing TADs using its highest-affinity binding sites (rex sites) to mediate long-range chromatin interactions (Crane et al. 2015). We found that the H4K20me2 demethylase activity of DPY-21 contributes to both the compaction of $\mathrm{X}$ and the DCC-driven remodeling of $\mathrm{X}$ topology.

Chromosome volume measurements performed in gut nuclei of wild-type and mutant adults showed that the fraction of total chromosome volume occupied by $\mathrm{X}$ increased by $30 \%$ in all three $d p y-21(\mathrm{JmjC})$ mutants $\left(P<10^{-6}\right.$, twosided Wilcoxon rank-sum test) (Brejc et al. 2017). In contrast, $\mathrm{X}$ volume was not significantly changed $(P=0.2)$ in a dosage compensation mutant ( $s d c-1$ (null)) that has normal H4K20me1 enrichment on X and comparably modest dosage compensation defects as in $d p y-21$ (JmjC) mutants. Thus, the increase in X-chromosome volume is not a byproduct of changes in gene expression, and H4K20me1 contributes directly to X-chromosome compaction.

The effect of H4K20me1 enrichment on the remodeling of X-chromosome topology was determined by investigating the timing of TAD boundary formation relative to the timing of DPY-21 binding to $\mathrm{X}$ and by genome-wide conformation capture experiments (Hi-C) to determine the position and degree of TAD boundary formation in $d p y$ 21(JmjC) mutants.

Fluorescence in situ hybridization (FISH) experiments revealed that the DCC-dependent TAD boundary at rex-14 started to form by the 80-120-cell stage and was well formed by the 180-250-cell stage, before DPY-21 was reliably detected on $\mathrm{X}$ chromosomes by immunofluorescence (Brejc et al. 2017). Thus, H4K20me2 demethylase activity is not essential to initiate the formation of DCCdependent TADs. However, Hi-C experiments comparing TADs in wild-type and $d p y-21(J m j C)$ mutants revealed that DCC-dependent TAD boundaries were diminished in the mutant (Fig. 6A-C). Insulation profiles showed that TAD boundaries were formed at the same 17 locations on $\mathrm{X}$ chromosomes of wild-type and mutant animals, but 

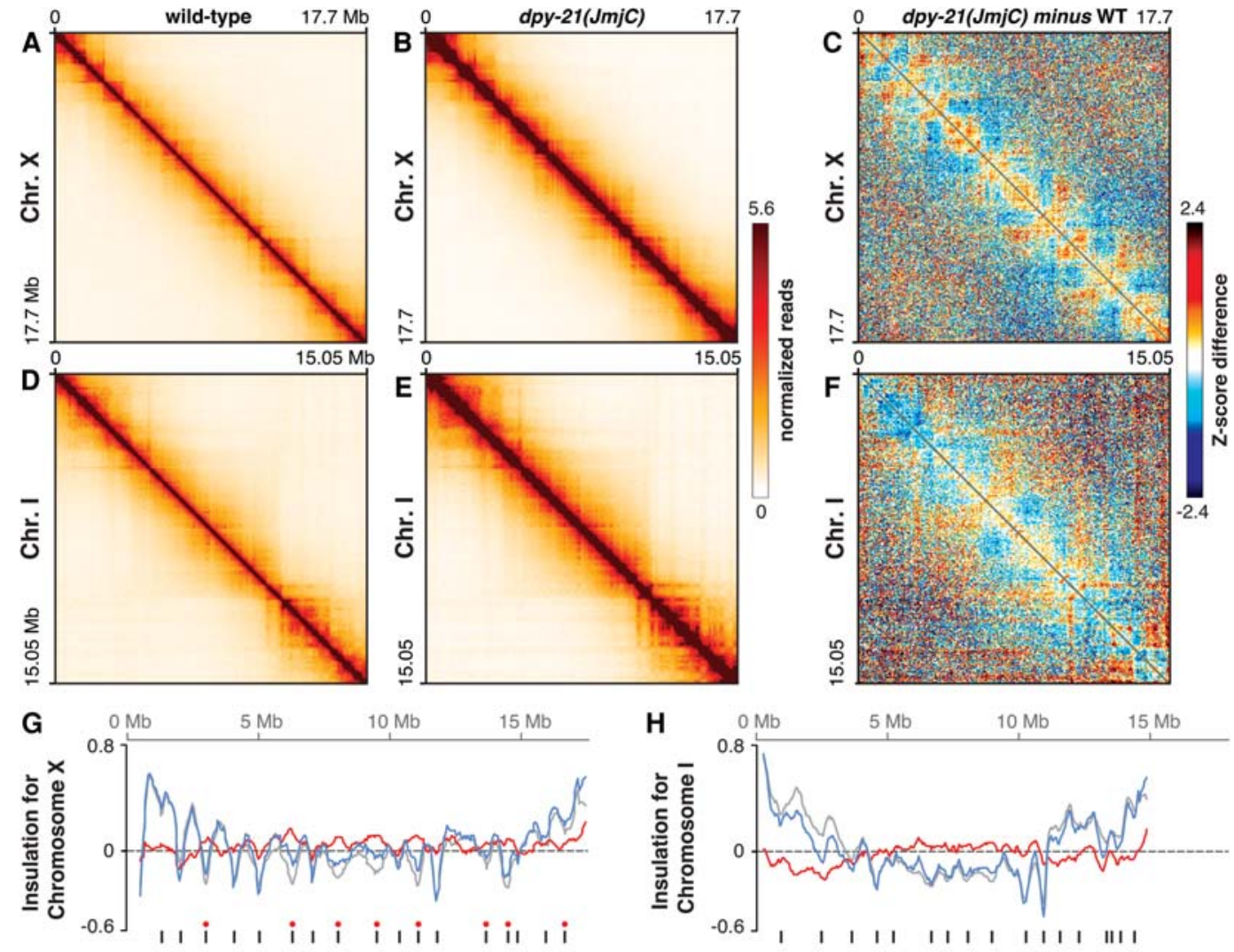

- wild-type $-d p y$-21(JmjC) mutant - Insulation difference: $d p y$-21(JmjC) minus WT
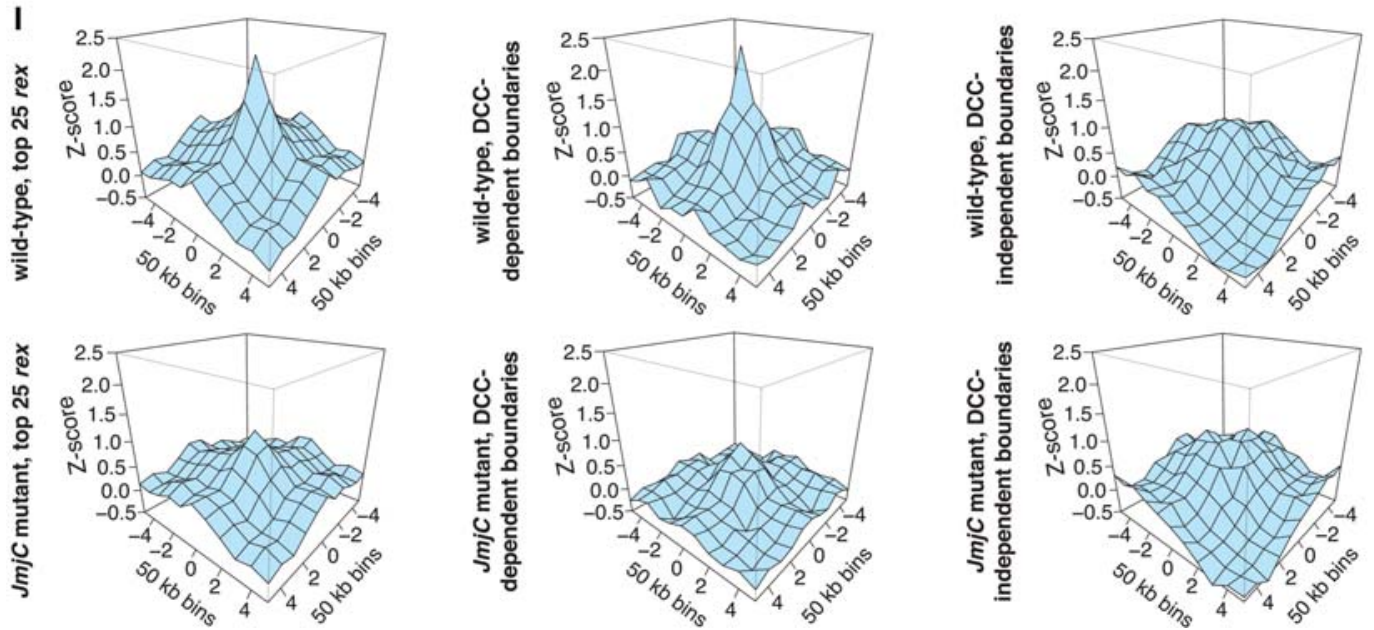

Figure 6. DPY-21 demethylase activity modulates $\mathrm{X}$-chromosome topology. $(A, B, D, E)$ Heat maps of Hi-C data binned at 50-kb resolution show chromatin interaction frequencies on chromosomes $\mathrm{X}$ and I in wild-type and $d p y-21$ (JmjC) mutant embryos. These heat maps show results from one of two replicates. Heat maps combining both replicates are presented in Brejc et al. (2017), with the same conclusions. $(C, F) Z$-score difference heat maps of Hi-C data in $A, B$ and $D, E$, respectively, binned at 50 -kb resolution show chromatin interactions that increase (orange-red) and decrease (blue) on $\mathrm{X}(\mathrm{C})$ and $\mathrm{I}(F)$ in $d p y$-2(JmjC) mutant versus wild-type embryos. $(G, H)$ Insulation plots for chromosomes X or I of wild-type (gray) or dpy-21(JmjC) mutant (blue) embryos and insulation difference plots (red) from data in $A-E$. Black bars, location of topologically associated domain (TAD) boundaries in wild-type embryos. Red dots, dosage compensation complex (DCC)-dependent boundaries greatly diminished or eliminated upon DCC depletion (Crane et al. 2015). Each has a high-affinity rex site. An insulation score reflects the cumulative interactions occurring across each interval. Minima denote areas of high insulation classified as TAD boundaries. The difference between insulation profiles of wild-type and $d p y-$ $21(\mathrm{JmjC})$ mutants reflects the change in boundary strength. An increase in insulation score at a TAD boundary means less insulation in the mutant, indicating a weakening of the boundary. DCC-dependent TAD boundaries on X were reduced in $d p y$-21(JmjC) mutants, but DCC-independent boundaries on X and autosomes were not significantly changed. $(I)$ Three-dimensional profiles of average Hi-C interaction frequencies (Z-scores) in 50-kb bins around pairs of top 25 rex sites, DCC-dependent boundaries on X, and DCC-independent boundaries on $\mathrm{X}$ in wild-type or $d p y-21(\mathrm{Jmj} C)$ mutant embryos. Profiles are centered at 0 . Interactions between rex sites and DCCdependent boundaries are reduced in demethylase mutants. (Adapted from Brejc et al. 2017.) 
the difference in insulation profiles showed that the strength of all eight DCC-dependent TAD boundaries on $\mathrm{X}$ was significantly reduced in $J m j C$ mutants (Fig. 6G; Brejc et al. 2017). In contrast, the nine DCC-independent TAD boundaries on $\mathrm{X}$ (Fig. 6G) and the TAD boundaries on autosomes (Fig. 6D-F,H) were not significantly weakened by the $d p y-21$ (JmjC) mutation (Brejc et al. 2017).

Analysis of Hi-C interaction frequencies ( $Z$-scores) revealed an underlying cause for the defect in TAD boundary formation. In $d p y-21(\mathrm{JmjC})$ mutants, interactions between sites within $1 \mathrm{Mb}$ were increased significantly, whereas interactions between sites $>1 \mathrm{Mb}$ apart were decreased significantly (Fig. 6C; Brejc et al. 2017). Among the reduced long-range interactions $(>1 \mathrm{Mb})$ were those between the DCC-dependent TAD boundaries and between the highest-affinity rex sites that mediate TAD boundary formation. Reduction in these interactions contributed to the loss in TAD boundary strength (Fig. 6I). In contrast, interactions between DCC-independent boundaries on X were unchanged (Fig. 6I), and interactions on autosomes showed moderate changes in the opposite direction (Fig. 6F).

These results support a two-tiered model for TAD formation during dosage compensation. In the first stage, the condensin DCC initiates TAD formation prior to DPY-21 recruitment and hence via a demethylase-independent mechanism that promotes long-range interactions between the highest-affinity DCC-binding sites. In the second stage, DPY-21 binds to $\mathrm{X}$ and catalyzes enrichment of H4K20me1, thereby enhancing long-range DNA interactions across $\mathrm{X}$. X-chromosome compaction is generally increased, and the increase in long-range interactions among rex sites strengthens TAD boundaries.

\section{IN GERM CELLS, H4K20me2 DEMETHYLASE ENRICHES H4K20me1 ON AUTOSOMES BY A DCC-INDEPENDENT MECHANISM TO PROMOTE CHROMOSOME COMPACTION}

As in somatic cells, H4K20me1 shows a dynamic pattern of enrichment in germ cells. H4K20me1 levels are high on all mitotic chromosomes in the gonad and become reduced as nuclei enter meiosis (Fig. 7A,B). By early pachytene, H4K20mel is enriched only on autosomes of both sexes and absent from $\mathrm{X}$ chromosomes (Fig. 7B), raising the question of whether DPY-21 also controls H4K20me1 levels in the germline, where the DCC does not assemble or function. In gonads of $d p y-21(\mathrm{JmjC})$ mutants, H4K20me1 levels remained high on mitotic chromosomes, but H4K20me1 was absent from all pachytene chromosomes, indicating that the JmjC demethylase is essential in germ cells for autosomal enrichment of H4K20me1 during meiosis but not mitosis (Fig.7A,B). The localization of DPY21 met all expectations for a demethylase that regulates autosomal levels of H4K20me1 during meiosis but not mitosis: DPY-21 bound to autosomes but not X chromosomes of pachytene nuclei and failed to bind mitotic chromosomes (Fig. 7A,C).

These findings prompted the question of whether DPY21 and H4K20me1 regulate chromosome compaction during germ cell development. A change in meiotic chromo- some compaction should be reflected in a change in length of the chromosome axis. Indeed, measurements of axis lengths in 3D for chromosomes $\mathrm{X}$ and $\mathrm{I}$ in wild-type and $d p y-21(J m j C)$ mutants revealed that $\mathrm{X}$ axis length was not different in the mutants, as predicted by the absence of H4K20me1 and DPY-21 (Fig. 7D). However, chromosome I axis length was extended by $20 \%$ in mutants (Fig. 7D), indicating that selective binding of DPY21, and hence H4K20me1 enrichment, regulates higherorder chromosome structure in germ cells. Because the key DCC subunits that recruit DPY-21 to X chromosomes in XX somatic cells are not expressed in the germline, the DPY-21 demethylase activity must operate via a DCCindependent mechanism using factors that either recruit DPY-21 to autosomes or repel it from X. Thus, DPY-21 is an adaptable chromatin regulator that is harnessed during development for distinct biological functions through different binding partners (Fig. 8). In both somatic cells and germ cells, H4K20me1 modulates 3D chromosome architecture, demonstrating the direct link between chromatin modification and higher-order chromosome structure.

\section{CONCLUSION}

We showed the function of chromatin modification in establishing higher-order chromosome structure during gene regulation. Moreover, discovery of ubiquitous H4K20me2 demethylases that act in worms and mammals to enhance H4K20me1 levels further expands our opportunity to dissect the dynamic regulation of H4K20 methylation essential for DNA replication, DNA damage response, chromosome segregation, gene regulation, and development. Prior studies suggested that H4K20 methylation was likely to be controlled by demethylases as well as previously characterized methyltransferases, but the H4K20me2/me3 demethylases responsible for such regulation had not been identified (van Nuland and Gozani 2016).

The finding that the DPY-21 and mROSBIN demethylases lack obvious DNA and chromatin-binding domains to confer target specificity provides the flexibility for these enzymes to be recruited to different genomic locations by diverse mechanisms to control essential nuclear processes. In general, though, only a limited number of DNA-binding factors are known to target histone demethylases to chromatin (Dimitrova et al. 2015), making the recruitment of an H4K20me2 demethylase to X chromosomes by a specialized condensin complex a highly tractable model. DCC binding and spreading distributes demethylase activity chromosome-wide. Thus, the DCC acts as an "eraser" of a prominent histone posttranslational modification, increasing H4K20me1 levels along X by activating an H4K20me2 demethylase rather than regulating an H4K20 methyltransferase.

DPY-21's role in chromatin modification further illustrates how dosage compensation evolved by co-opting conserved machinery used in other biological processes for the new task of fine-tuning X-chromosome expression. Our observations suggest that other condensin and structural maintenance of chromosomes (SMC) complexes 


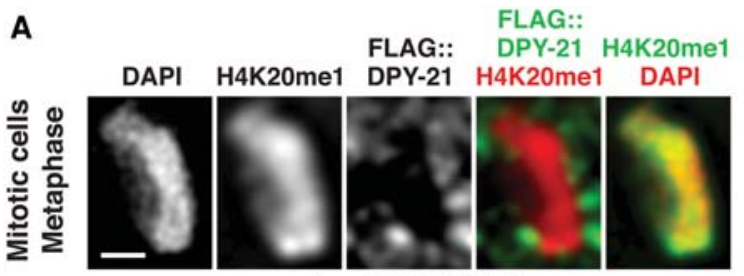

dpy-21(5'-FLAG)
(1)

B

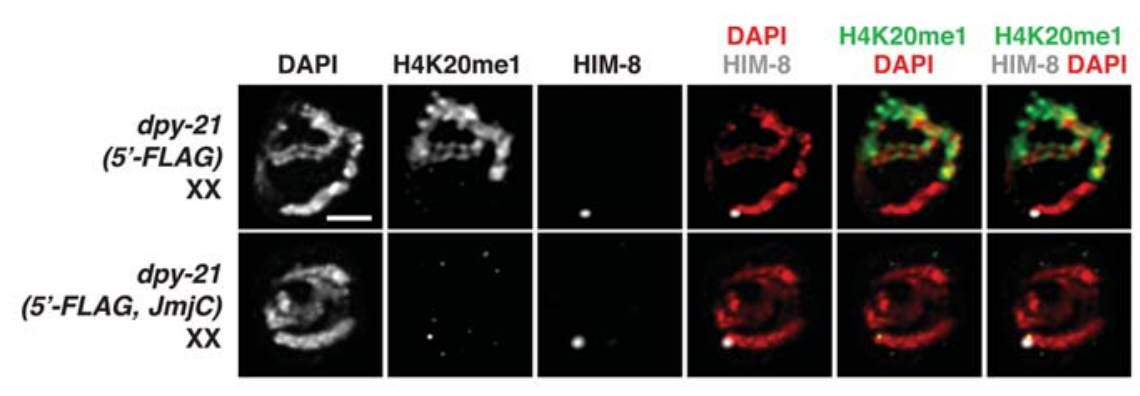

C

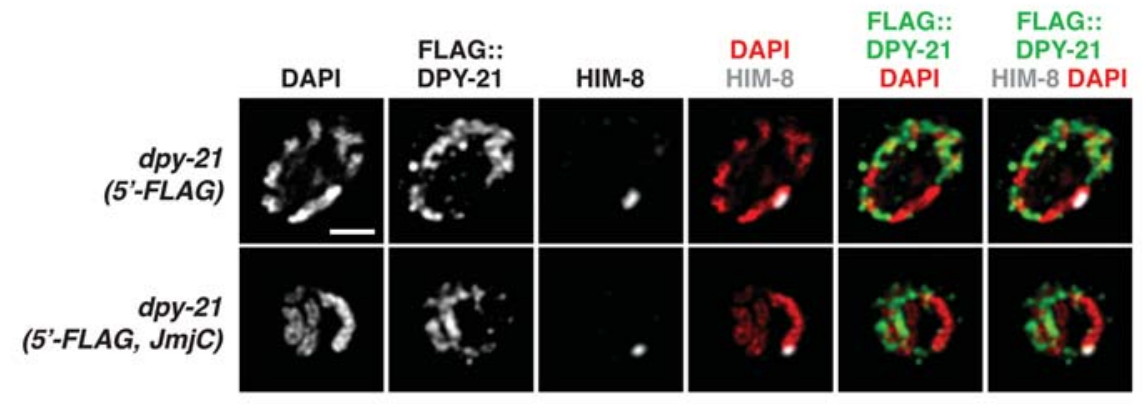

D

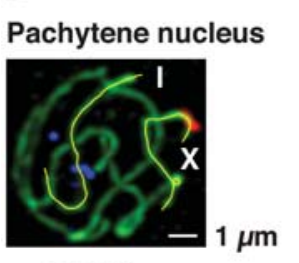

- HTP-3

- HIM-8 on $X$

- Chr. I FISH

$$
\text { wild-type }
$$

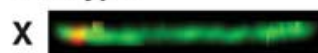

$5.9+/-0.12 \mu \mathrm{m}$

I

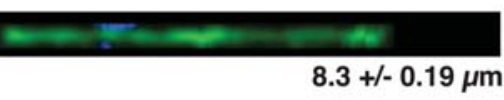

$d p y-21(J m j C)$

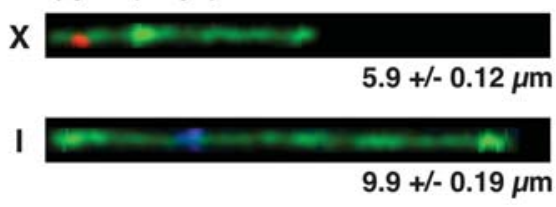

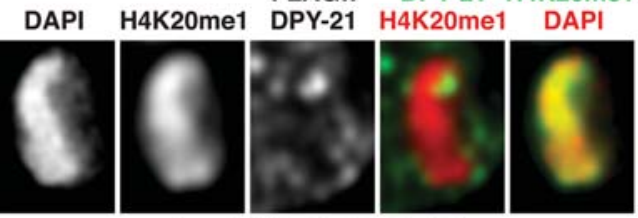

dpy-21(5'-FLAG JmjC)

FLAG::

FLAG:: DPY-21 H4K20me1 

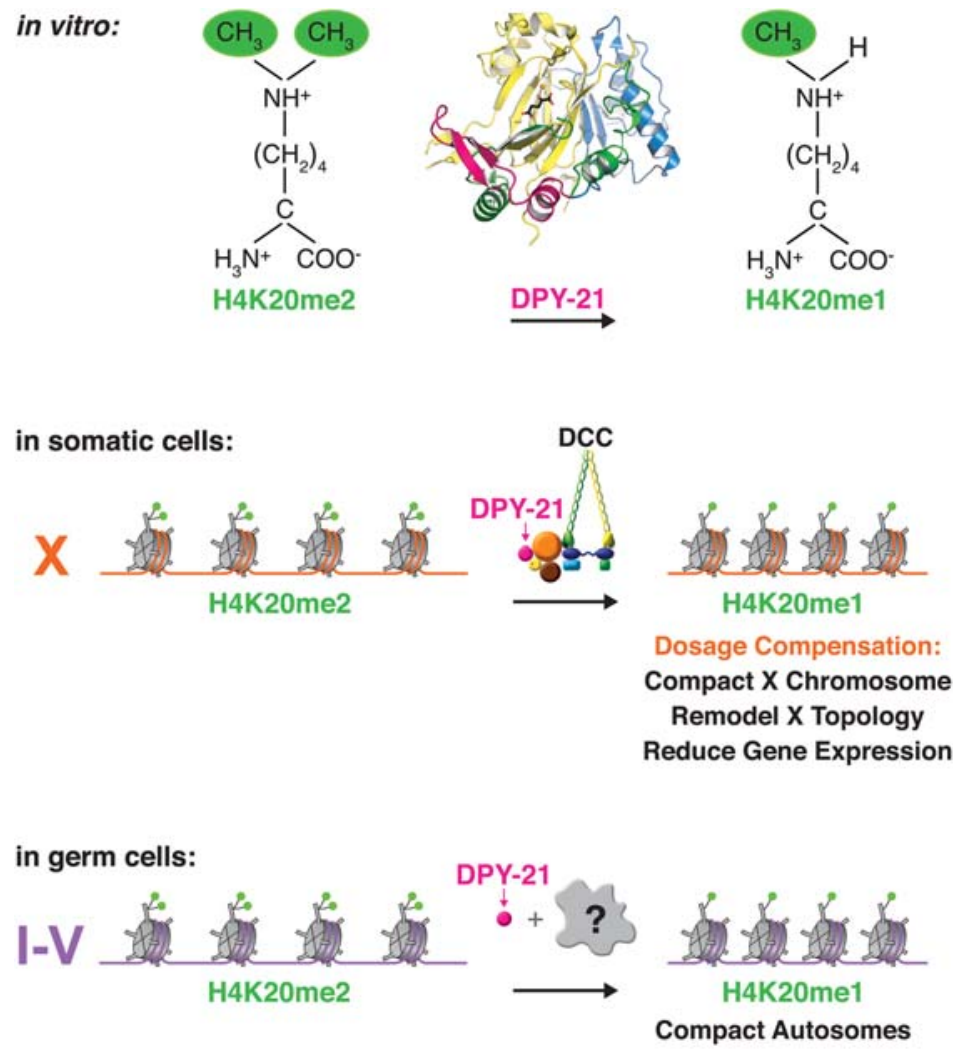

Figure 8. An H4K20me2 histone demethylase regulates 3D chromosome structure and gene expression by modulating the dynamic enrichment of H4K20me1. The $1.8 \AA$ crystal structure and biochemical activity of DPY-21 revealed a new, highly conserved H4K20me2 JmjC demethylase subfamily that converts H4K20me2 to H4K20me1 in vitro. In somatic cells, DPY-21 binds to X chromosomes via the dosage compensation complex (DCC) and enriches H4K20me1 to repress gene expression. The H4K20me1 enrichment controls the higher-order structure of $\mathrm{X}$ chromosomes by facilitating compaction and topologically associated domain (TAD) formation. In germ cells, DPY-21 enriches HK20me1 on autosomes in a DCC-independent manner to promote chromosome compaction. (Adapted from Brejc et al. 2017.)

could act as scaffolds to recruit proteins with chromosome-modifying activities.

The enrichment of H4K20me1 on the inactive X chromosome of female mice (Kohlmaier et al. 2004) makes our discoveries directly relevant for mammalian development. The long noncoding RNA XIST, the trigger of mammalian $\mathrm{X}$ inactivation, induces accumulation of H4K20me1 on $\mathrm{X}$, but $\mathrm{X}$ inactivation per se is not required for H4K20me1 enrichment, suggesting that H4K20me1 might contribute to establishing inactivation. Consistent with this interpretation, knockout of the mouse H4K20me1 methyltransferase causes decondensation of X (Oda et al. 2009). Thus, our observations offer new directions for unraveling the regulation and function of $\mathrm{H} 4 \mathrm{~K} 20 \mathrm{me} 1$ in X-chromosome inactivation and other mechanisms of gene control that act over long distances. Our findings also provide new avenues for understanding the mechanisms by which chromatin modifications help remodel higher-order chromosome structure during development.

\section{ACKNOWLEDGMENTS}

We thank Deborah Stalford for drafting the figures. This work was supported by National Institutes of Health grant
R01 GM030702 to B.J.M. and by the Howard Hughes Medical Institute.

\section{REFERENCES}

Beck DB, Oda H, Shen SS, Reinberg D. 2012. PR-Set7 and H4K20me1: At the crossroads of genome integrity, cell cycle, chromosome condensation, and transcription. Genes Dev 26: 325-337.

Blanchard DP, Georlette D, Antoszewski L, Botchan MR. 2014. Chromatin reader L(3)mbt requires the Myb-MuvB/DREAM transcriptional regulatory complex for chromosomal recruitment. Proc Natl Acad Sci 111: E4234-E4243.

Boettiger AN, Bintu B, Moffitt JR, Wang S, Beliveau BJ, Fudenberg G, Imakaev M, Mirny LA, Wu C-T, Zhuang X. 2016. Super-resolution imaging reveals distinct chromatin folding for different epigenetic states. Nature 529: 418422.

Brejc K, Bian Q, Uzawa S, Wheeler BS, Anderson EC, King DS, Kranzusch PJ, Preston CG, Meyer BJ. 2017. Dynamic control of $\mathrm{X}$ chromosome conformation and repression by a histone H4K20 demethylase. Cell 171: 85-102 e123.

Chen Z, Zang J, Whetstine J, Hong X, Davrazou F, Kutateladze TG, Simpson M, Mao Q, Pan CH, Dai S, et al. 2006. Structural insights into histone demethylation by JMJD2 family members. Cell 125: 691-702.

Crane E, Bian Q, McCord RP, Lajoie BR, Wheeler BS, Ralston EJ, Uzawa S, Dekker J, Meyer BJ. 2015. Condensin-driven 
remodelling of X chromosome topology during dosage compensation. Nature 523: 240-244.

Csankovszki G, Collette K, Spahl K, Carey J, Snyder M, Petty E, Patel U, Tabuchi T, Liu H, McLeod I, et al. 2009. Three distinct condensin complexes control C. elegans chromosome dynamics. Curr Biol 19: 9-19.

Davis TL, Meyer BJ. 1997. SDC-3 coordinates the assembly of a dosage compensation complex on the nematode $\mathrm{X}$ chromosome. Development 124: 1019-1031.

Dawes HE, Berlin DS, Lapidus DM, Nusbaum C, Davis TL, Meyer BJ. 1999. Dosage compensation proteins targeted to $\mathrm{X}$ chromosomes by a determinant of hermaphrodite fate. Science 284: 1800-1804.

Dekker J, Mirny L. 2016. The 3D genome as moderator of chromosomal communication. Cell 164: 1110-1121.

Dimitrova E, Turberfield AH, Klose RJ. 2015. Histone demethylases in chromatin biology and beyond. EMBO Rep 16: 1620-1639.

Francis NJ, Kingston RE, Woodcock CL. 2004. Chromatin compaction by a Polycomb group protein complex. Science 306: 1574-1577.

Hagstrom KA, Holmes VF, Cozzarelli NR, Meyer BJ. 2002. C. elegans condensin promotes mitotic chromosome architecture, centromere organization, and sister chromatid segregation during mitosis and meiosis. Genes Dev 16: 729-742.

Hirano T. 2016. Condensin-based chromosome organization from bacteria to vertebrates. Cell 164: 847-857.

Holm L, Rosenstrom P. 2010. Dali server: Conservation mapping in 3D. Nucleic Acids Res 38: W545-W549.

Hsu DR, Chuang PT, Meyer BJ. 1995. DPY-30, a nuclear protein essential early in embryogenesis for Caenorhabditis elegans dosage compensation. Development 121: 3323-3334.

Jans J, Gladden JM, Ralston EJ, Pickle CS, Michel AH, Pferdehirt RR, Eisen MB, Meyer BJ. 2009. A condensin-like dosage compensation complex acts at a distance to control expression throughout the genome. Genes Dev 23: 602-618.

Jorgensen S, Schotta G, Sorensen CS. 2013. Histone H4 lysine 20 methylation: key player in epigenetic regulation of genomic integrity. Nucleic Acids Res 41: 2797-2806.

Kalashnikova AA, Porter-Goff ME, Muthurajan UM, Luger K, Hansen JC. 2013. The role of the nucleosome acidic patch in modulating higher order chromatin structure. JR Soc Interface 10: 20121022 .

Klein RD, Meyer BJ. 1993. Independent domains of the SDC-3 protein control sex determination and dosage compensation in C. elegans. Cell 72: 349-364.

Kohlmaier A, Savarese F, Lachner M, Martens J, Jenuwein T, Wutz A. 2004. A chromosomal memory triggered by Xist regulates histone methylation in X inactivation. PLoS Biol 2: E171.

Koscielny G, Yaikhom G, Iyer V, Meehan TF, Morgan H, Atienza-Herrero J, Blake A, Chen CK, Easty R, Di Fenza A, et al. 2014. The international mouse phenotyping consortium web portal, a unified point of access for knockout mice and related phenotyping data. Nucleic Acids Res 42: D802-D809.

Kramer M, Kranz AL, Su A, Winterkorn LH, Albritton SE, Ercan S. 2015. Developmental dynamics of X-chromosome dosage compensation by the DCC and H4K20me1 in C. elegans. PLoS Genet 11: e1005698.

Kundu S, Ji F, Sunwoo H, Jain G, Lee JT, Sadreyev RI, Dekker J, Kingston RE. 2017. Polycomb repressive complex 1 generates discrete compacted domains that change during differentiation. Mol Cell 65: 432-446 e435.

Lau AC, Nabeshima K, Csankovszki G. 2014. The C. elegans dosage compensation complex mediates interphase $\mathrm{X}$ chromosome compaction. Epigenetics Chromatin 7: 31.

Liu T, Rechtsteiner A, Egelhofer TA, Vielle A, Latorre I, Cheung MS, Ercan S, Ikegami K, Jensen M, Kolasinska-Zwierz P, et al. 2011. Broad chromosomal domains of histone modification patterns in C. elegans. Genome Res 21: 227-236.

Liu W, Tanasa B, Tyurina OV, Zhou TY, Gassmann R, Liu WT, Ohgi KA, Benner C, Garcia-Bassets I, Aggarwal AK, et al. 2010. PHF8 mediates histone H4 lysine 20 demethylation events involved in cell cycle progression. Nature 466: 508 512.

Lu X, Simon MD, Chodaparambil JV, Hansen JC, Shokat KM, Luger K. 2008. The effect of H3K79 dimethylation and H4K20 trimethylation on nucleosome and chromatin structure. Nat Struct Mol Biol 15: 1122-1124.

Markolovic S, Leissing TM, Chowdhury R, Wilkins SE, Lu X, Schofield CJ. 2016. Structure-function relationships of human JmjC oxygenases-demethylases versus hydroxylases. Curr Opin Struct Biol 41: 62-72.

Mets DG, Meyer BJ. 2009. Condensins regulate meiotic DNA break distribution, thus crossover frequency, by controlling chromosome structure. Cell 139: 73-86.

Meyer BJ. 2010. Targeting X chromosomes for repression. Curr Opin Genet Dev 20: 179-189.

Miller LM, Plenefisch JD, Casson LP, Meyer BJ. 1988. xol-1: A gene that controls the male modes of both sex determination and X chromosome dosage compensation in C. elegans. Cell 55: $167-183$.

Nonet ML, Meyer BJ. 1991. Early aspects of Caenorhabditis elegans sex determination and dosage compensation are regulated by a zinc-finger protein. Nature 351: 65-68.

Nora EP, Dekker J, Heard E. 2013. Segmental folding of chromosomes: A basis for structural and regulatory chromosomal neighborhoods? Bioessays 35: 818-828.

Nora EP, Goloborodko A, Valton AL, Gibcus JH, Uebersohn A, Abdennur N, Dekker J, Mirny LA, Bruneau BG. 2017. Targeted degradation of CTCF decouples local insulation of chromosome domains from genomic compartmentalization. Cell 169: 930-944 e922.

Oda H, Okamoto I, Murphy N, Chu J, Price SM, Shen MM, Torres-Padilla ME, Heard E, Reinberg D. 2009. Monomethylation of histone H4-lysine 20 is involved in chromosome structure and stability and is essential for mouse development. Mol Cell Biol 29: 2278-2295.

Pesavento JJ, Yang H, Kelleher NL, Mizzen CA. 2008. Certain and progressive methylation of histone $\mathrm{H} 4$ at lysine 20 during the cell cycle. Mol Cell Biol 28: 468-486.

Pferdehirt RR, Kruesi WS, Meyer BJ. 2011. An MLL/COMPASS subunit functions in the C. elegans dosage compensation complex to target $\mathrm{X}$ chromosomes for transcriptional regulation of gene expression. Genes Dev 25: 499-515.

Qi HH, Sarkissian M, Hu GQ, Wang Z, Bhattacharjee A, Gordon DB, Gonzales M, Lan F, Ongusaha PP, Huarte M, et al. 2010. Histone H4K20/H3K9 demethylase PHF8 regulates zebrafish brain and craniofacial development. Nature 466: 503-507.

Rhind NR, Miller LM, Kopczynski JB, Meyer BJ. 1995. xol-1 acts as an early switch in the $C$. elegans male/hermaphrodite decision. Cell 80: 71-82.

Schuettengruber B, Bourbon HM, Di Croce L, Cavalli G. 2017. Genome regulation by Polycomb and trithorax: 70 years and counting. Cell 171: 34-57.

Soshnev AA, Josefowicz SZ, Allis CD. 2016. Greater than the sum of parts: Complexity of the dynamic epigenome. Mol Cell 62: 681-694.

Stender JD, Pascual G, Liu W, Kaikkonen MU, Do K, Spann NJ, Boutros M, Perrimon N, Rosenfeld MG, Glass CK. 2012. Control of proinflammatory gene programs by regulated trimethylation and demethylation of histone H4K20. Mol Cell 48: $28-38$.

Takahashi T, Tanaka H, Iguchi N, Kitamura K, Chen Y, Maekawa M, Nishimura H, Ohta H, Miyagawa Y, Matsumiya K, et al. 2004. Rosbin: a novel homeobox-like protein gene expressed exclusively in round spermatids. Biol Reprod 70: 1485-1492.

Trojer P, Li G, Sims RJ 3rd, Vaquero A, Kalakonda N, Boccuni P, Lee D, Erdjument-Bromage H, Tempst P, Nimer SD, et al. 2007. L3MBTL1, a histone-methylation-dependent chromatin lock. Cell 129: 915-928.

van Nuland R, Gozani O. 2016. Histone H4 Lysine 20 (H4K20) methylation, expanding the signaling potential of the proteome one methyl moiety at a time. Mol Cell Proteomics 15: 755-764.

Vielle A, Lang J, Dong Y, Ercan S, Kotwaliwale C, Rechtsteiner A, Appert A, Chen QB, Dose A, Egelhofer T, et al. 2012. 


\section{H4K20me2 DEMETHYLASE CONTROLS CHROMOSOME TOPOLOGY AND EXPRESSION 291}

H4K20me1 contributes to downregulation of X-linked genes for C. elegans dosage compensation. PLoS Genet 8: e1002933.

Vieux-Rochas M, Fabre PJ, Leleu M, Duboule D, Noordermeer D. 2015. Clustering of mammalian Hox genes with other H3K27me3 targets within an active nuclear domain. Proc Natl Acad Sci 112: 4672-4677.

Wang J, Telese F, Tan Y, Li W, Jin C, He X, Basnet H, Ma Q, Merkurjev D, Zhu X, et al. 2015. LSD1n is an H4K20 demeth- ylase regulating memory formation via transcriptional elongation control. Nat Neurosci 18: 1256-1264.

Wells MB, Snyder MJ, Custer LM, Csankovszki G. 2012. Caenorhabditis elegans dosage compensation regulates histone H4 chromatin state on X chromosomes. Mol Cell Biol 32: $1710-1719$.

Yonker SA, Meyer BJ. 2003. Recruitment of C. elegans dosage compensation proteins for gene-specific versus chromosomewide repression. Development 130: 6519-6532. 


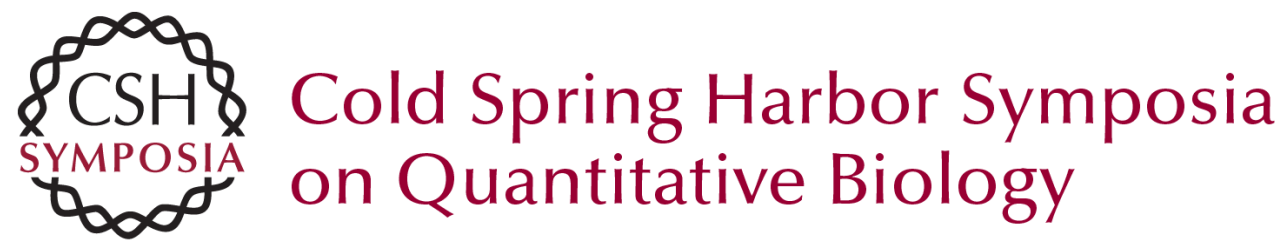

\section{Dynamic Control of Chromosome Topology and Gene Expression by a Chromatin Modification}

Qian Bian, Erika C. Anderson, Katjusa Brejc, et al.

Cold Spring Harb Symp Quant Biol 2017 82: 279-291 originally published online February 22, 2018

Access the most recent version at doi:10.1101/sqb.2017.82.034439

References This article cites 51 articles, 17 of which can be accessed free at: http://symposium.cshlp.org/content/82/279.full.html\#ref-list-1

Creative This article is distributed under the terms of the

Commons http://creativecommons.org/licenses/by-nc/4.0/, which permits reuse and

License redistribution, except for commercial purposes, provided that the original author and source are credited.

Email Alerting Receive free email alerts when new articles cite this article - sign up in Service the box at the top right corner of the article or click here. 